\title{
The Office Jungle: \\ Exploring Unusual Ways of Working through Bodily Experimentations
}

Ida Damen ${ }^{1,{ }^{*}}$, Ingmar Nieuweboer ${ }^{1,{ }^{*}}$, Hans Brombacher ${ }^{1}$, Pieter van Wesemael ${ }^{2}$, Steven $\operatorname{Vos}^{1,3}$ and Carine Lallemand ${ }^{1,4,{ }^{*}}$

${ }^{1}$ Eindhoven University of Technology, Industrial Design, the Netherlands

${ }^{2}$ Eindhoven University of Technology, Built Environment, the Netherlands ${ }^{3}$ School of Sport Studies, Fontys University of Applied Sciences, the Netherlands

${ }^{4}$ University of Luxembourg, HCI research group, Esch-sur-Alzette, Luxembourg

Corresponding author: a.a.j.m.damen@tue.nl

\section{ABSTRACT}

Modern office environments foster sitting, a major public health risk, with physical inactivity being the fourth cause of death worldwide. This provocative pictorial presents the design explorations and bodily experimentations culminating in The Office Jungle, a critical and speculative redesign of the office environment that encourages physical activity by embracing wildness. The Office Jungle is a design exemplar of a "wild" office space presented as a suspended geodesic structure. It is built to experienc e how our office environment and our behaviour at work affect each other. We advocate that bringing wildness into office spaces will create more durable office environments that foster movement. With this pictorial, we aim to spark discussion amongst designers to think in new ways and to consider new opportunities to design for workplaces that integrate physical activity with work.

Authors Keywords

Office environment; Sedentary Behavior; Design for Wildness;

Speculative design; Bodystorming.

\section{CSS Concepts}

- Human-centered computing Interaction paradigms

Permission to make digital or hard copies of part or all of this work for personal or classroom use is granted without fee provided that copies are not made or distributed for profit or commercial advantage and that copies bear this notice and the full citation on the first page. Copyrights for thirdparty components of this work must be honored. For all other uses, contact the Owner/Author.

DIS '21, June 28-July 2, 2021, Virtual Event, USA

(C) 2021 Copyright is held by the owner/author(s).

78-1-4503-8476-6/21/06.

https://doi.org/10.1145/3461778.3462062

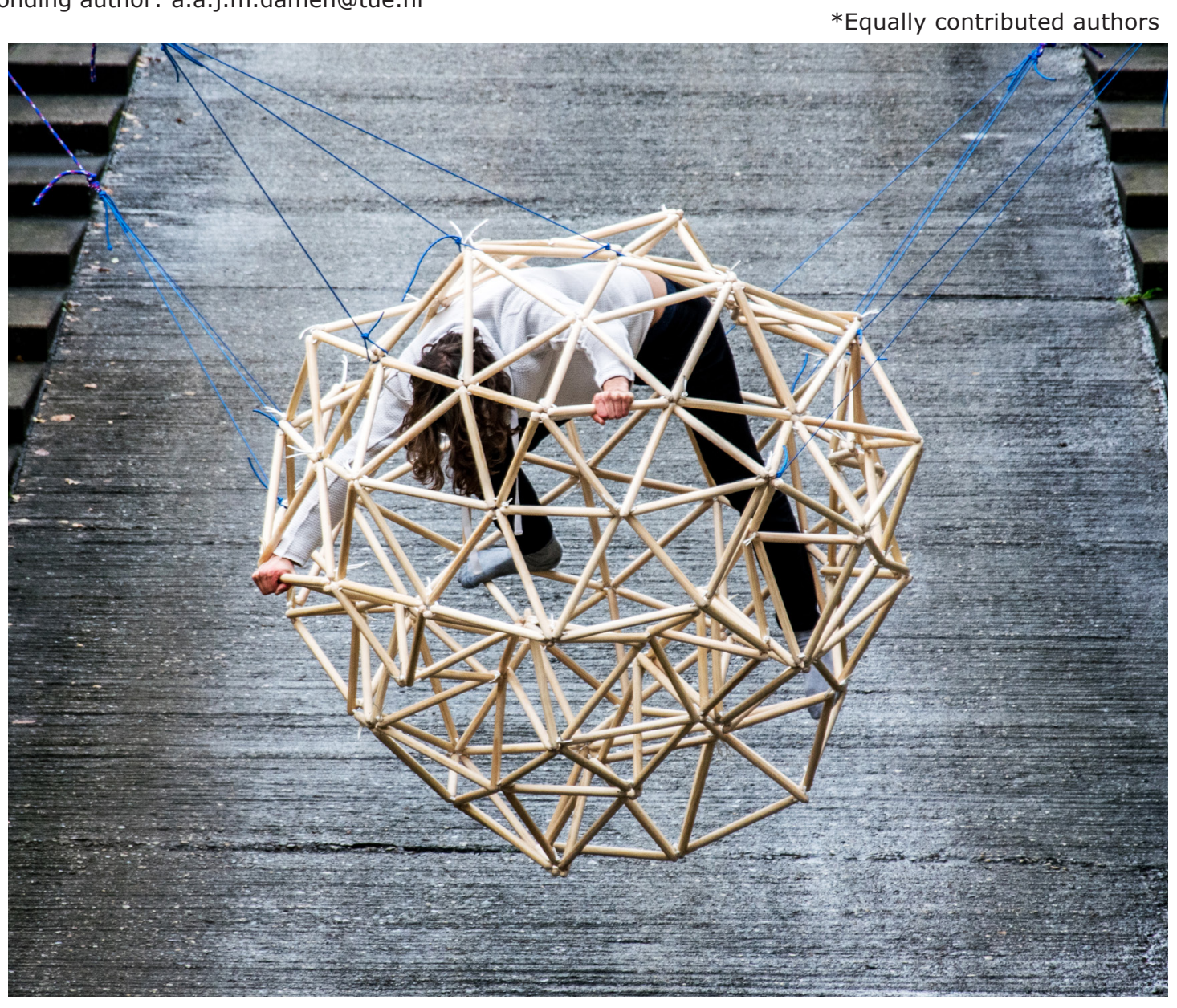




\section{INTRODUCTION}

Automatization of work tasks and processes have changed the way we work. Within office settings, there is little need for physical activity or being outdoors. Our environment is created for us to be as efficient and physically inactive as possible. Consequently, we harm our health and wellbeing and are in desperate need to restore the health-work balance. To achieve this, we need to create a more sustainable office environment that fosters movement instead of sitting. To combat the negative health effects of prolonged sitting at work, a myriad of technologies and digital tools to reduce sedentary behavior have been developed over recent years [see the scoping reviews by 4,10 ]. However, the vast majority of these interventions approach physical activity as a break from work [4]. Therefore, physical activity in the office environment is often perceived to be in competition with work productivity and efficiency.

With this provocative pictorial, we present "The Office Jungle" as a critical and speculative design to challenge the existing views on office work and office design. We aim to spark discussion on current workstyles, work practices and the way we design for this context. With our work, we call for a more holistic approach to facilitate physical activity in the office environment. As argued by Levine, workplaces should be designed to promote physical activity instead of sitting as the default posture [12]. To promote physical activity at the workplace, Probst et al. suggest a "paradigm shift in workplace design that involves the smooth integration of hardware- and software-related structural elements to provide opportunities for office workers to seamlessly change between different work environments." [14].

Looking at the office context from the lens of speculative or critical design might open up new perspectives. Speculative design enables us to think about possible futures, and questions current practices [1], tools, approaches and concepts. Similarly, Malpass explains how interrogative, discursive and experimental approaches, often adopted in critical designs, can challenge the status quo [13]. Despite a growing body of design work to reduce sedentary behavior in the office setting [4], there is a relative dearth of speculative and critical designs in this context. Amongst the designs developed to make users critically reflect on their sedentary work style, Tobiasson et al., developed the 'Irritating chair', whose sharp spikes rise after a prolonged period of sitting [15]. In the same vein, the shape-changing 'Productivity Chair' uses computationally controlled discomfort when a user is not productive [9]. With this design, Hemmert et al. criticize the trend of workplace surveillance for productivity maximization. A third example using the office chair as a stereotypical artefact embodying a critique of the status quo is Ivy [6], an office chair that represents employees' sitting time through growing ivy strands, eventually yet aesthetically rooting them to their seats. Other designers attempted to rethink the office environment in order to reduce sedentary behaviour: PositionPeak [5] is a set of unconventional office meeting furniture triggering position changes. It was inspired by another project that has raised discussion: 'the End of Sitting' [2]. This workplace landscape composed of glacier-like series of boulders and surfaces without any chairs and desks, allows for different work postures such as laying, standing or leaning. In line with The Office Jungle, it extends and questions the conventional limits of working environments and provides an alternative workplace that encourages a more active and healthier lifestyle through upright working.

In this pictorial, we take the readers on a lively journey exploring unconventional ways of working, from wearable to gymnastic-like bodystorming, to underwater trials and large-scale prototype construction. Through this visual evocation of our design process, we showcase the benefits of bodily experimentation in unusual directions. The end-result opens discussions around the ability of office workspaces to offer more full body and dynamic experiences. It also invites the $\mathrm{HCI}$ and design community to communicate openness to consider alternative and imaginative perspectives on embodied and tangible interaction $[7,11]$.

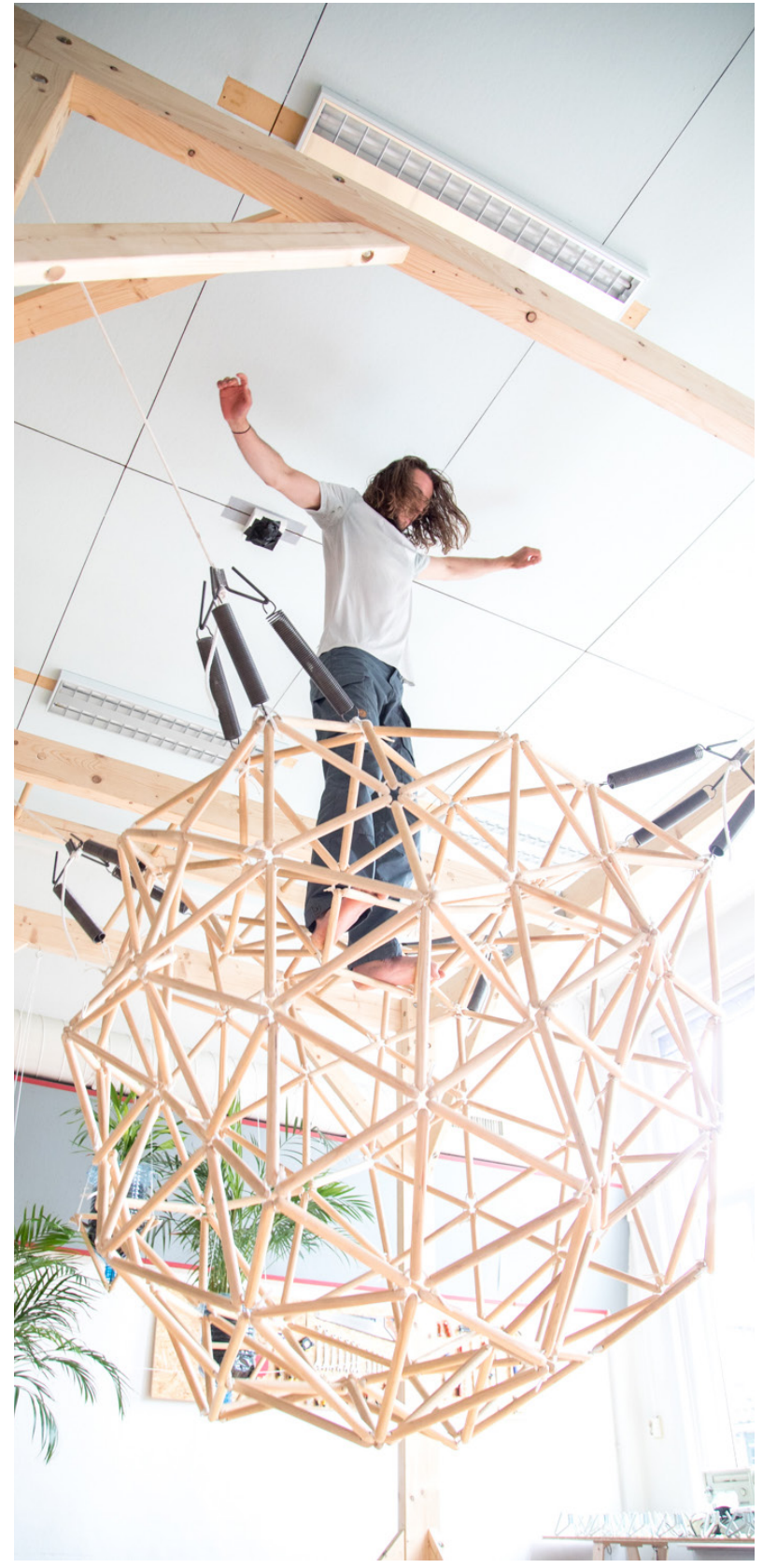




\section{EXPLORING WILDNESS IN OFFICE WORK}

\section{Explorations Through Bodily Experimentation}

A first step in creating The Office Jungle, was generating experiences of alternative ways of working through first-person explorations. These explorations were guided by the words given to Merleau-Ponty "We know not through our intellect but through our experience". The experiments were partly run in parallel, to stimulate creativity and allow cross-fertilization. Our embodied design experiments included exploration of various sitting position when working on a laptop, a low-fi prototype of a laptop-arm-mount, bodystorming experiments, and an underwater office experiment. Performing these explorations in public was also a way to provoke and trigger debate on this timely topic.

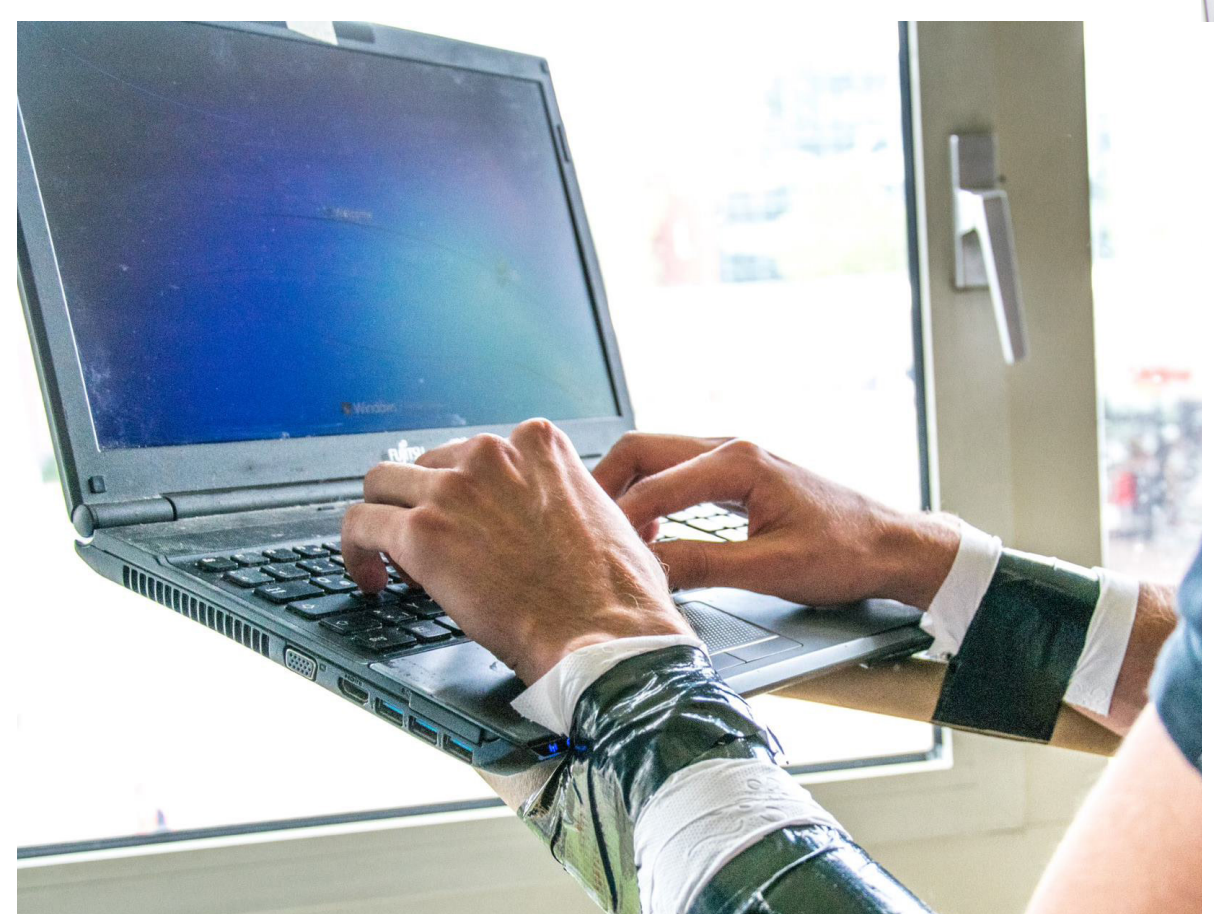

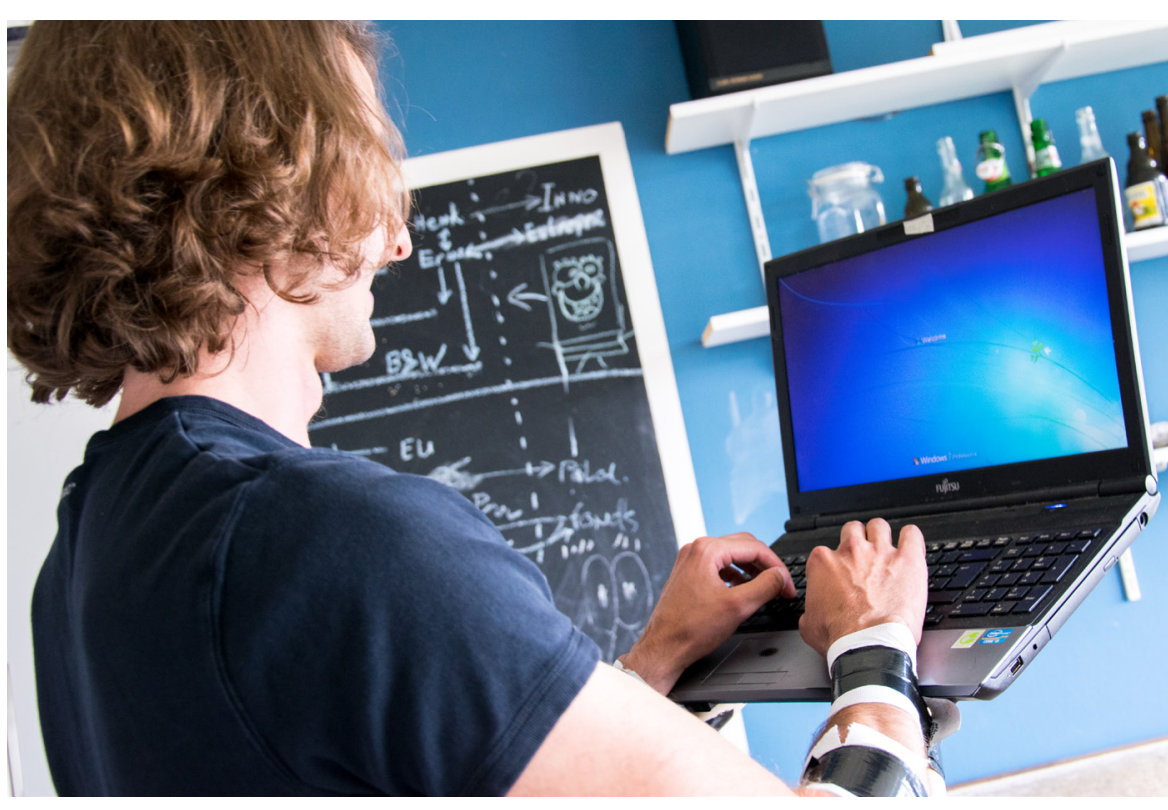

Exploration 2: Laptop-arm-mount

\section{Exploration 1: Different ways of Sitting while Working on a Laptop}

In an early exploration, we explored dozens of ways of sitting while working on a laptop. This aimed at representing and feeling that contrary to the standards imposed by traditional office design, there is not only one way of sitting at work. Posture changes were a first idea towards rethinking ways of working. While we could have speculated at this stage on new technologies that would free workers from the constraints of laptops, we decided to keep these. Holding it was however not always an easy task, as these devices also have been designed based on the assumption of being laid on flat and stable surfaces. These insights inspired our second exploration.

\section{Exploration 2: Laptop-arm-mount}

The laptop-arm-mount was developed to allow for more freedom of movement while working on a laptop. Using duct tape, wooden sticks and straps, one of the authors attached a laptop to his arms, creating a sort of mobile standing desk station. This experiment provided insights in how add-ons could facilitate alternative use of a laptop and how walkability during laptop use could improve. However, it also gave a negative feeling of restriction due to the arm movement limitations. 

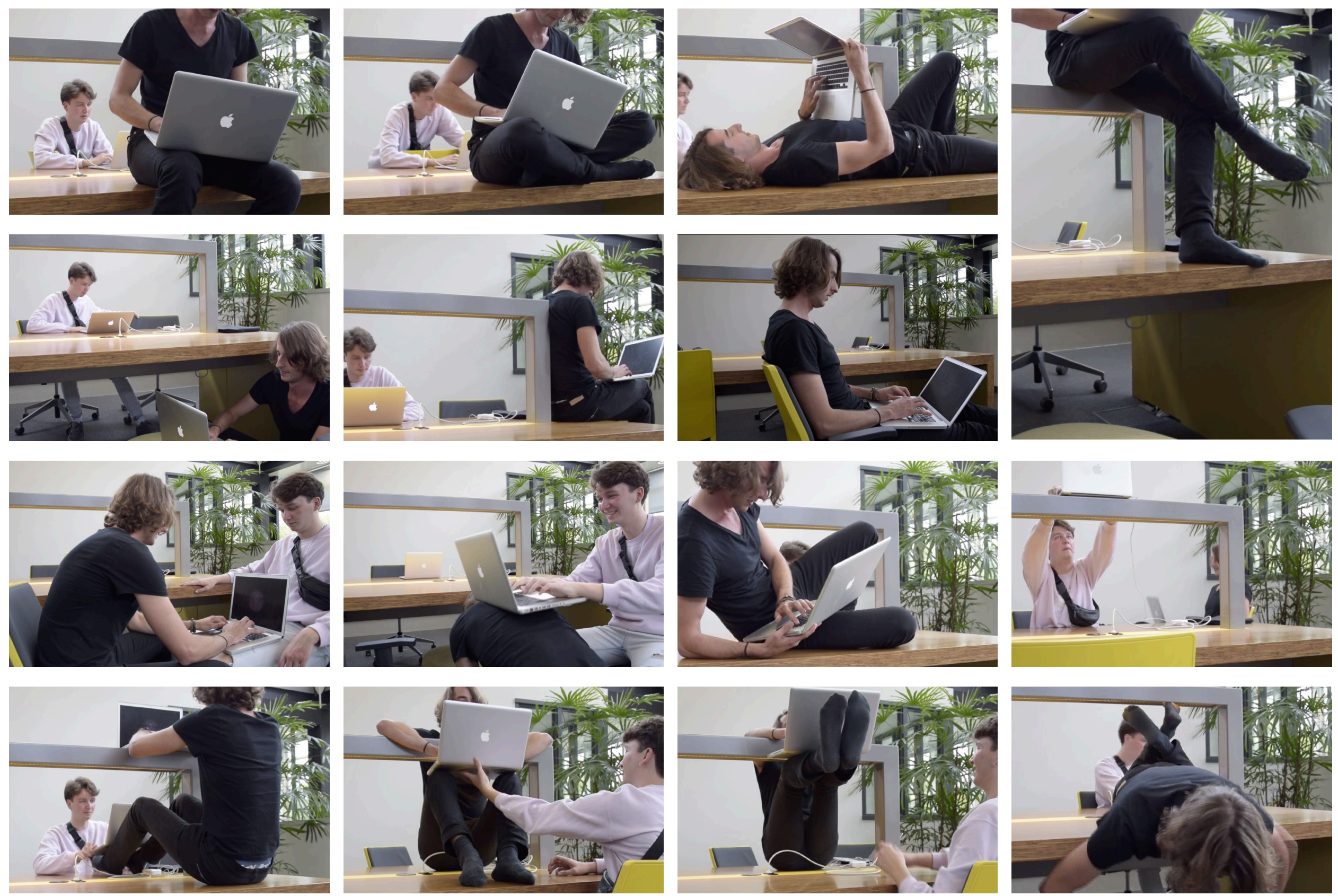

Exploration 1: Different ways of sitting while working on a laptop 


\section{Exploration 3: Humanized Work Units}

In a bodystorming experiment, eight participants split in two sessions were given the assignment to use their bodies as furniture and accommodate one person to work on his/her laptop. Two of them were not allowed to touch the ground. Several positions and group formations were tested. With groups of two, three and five people, multiple fully 'humanised work units' were built. Participants had to think out-of-the-box to achieve the goal by respecting the constraints.

They felt rather challenged and amused. For the person holding the laptop and attempting to work (and the person who ended up assisting her by serving as a laptop stand), the main observation was how stimulating yet distracting a moving and unstable environment was to stay focused. By exploring how people could act as furniture, we were able to experience different working postures, but above all got intrigued by how an organic and changing environment challenges you to think about how much safety and rigor is actually needed to work and think.

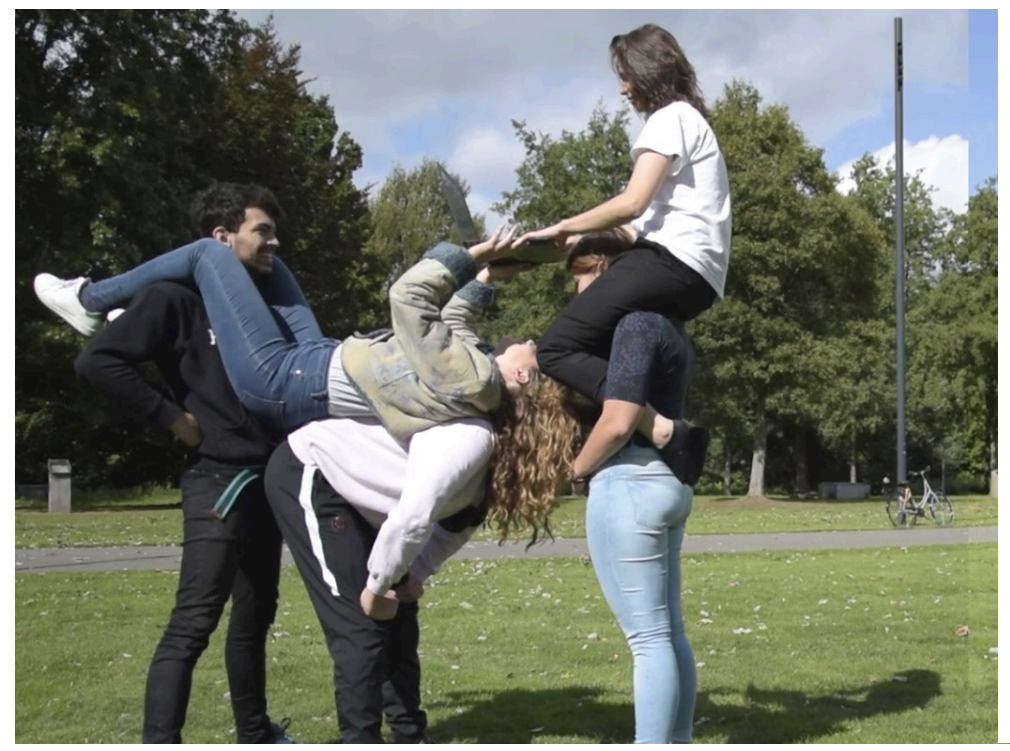

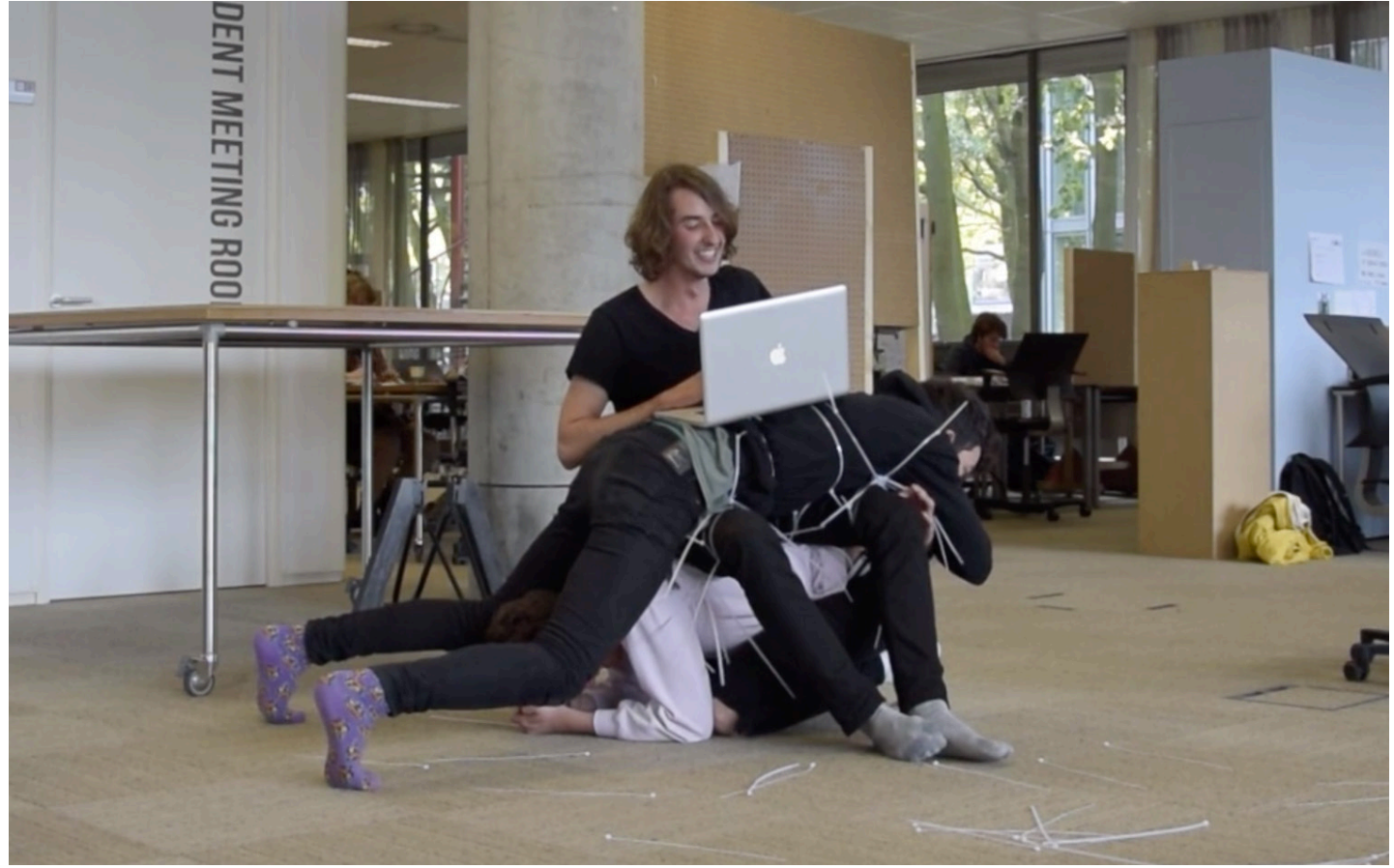
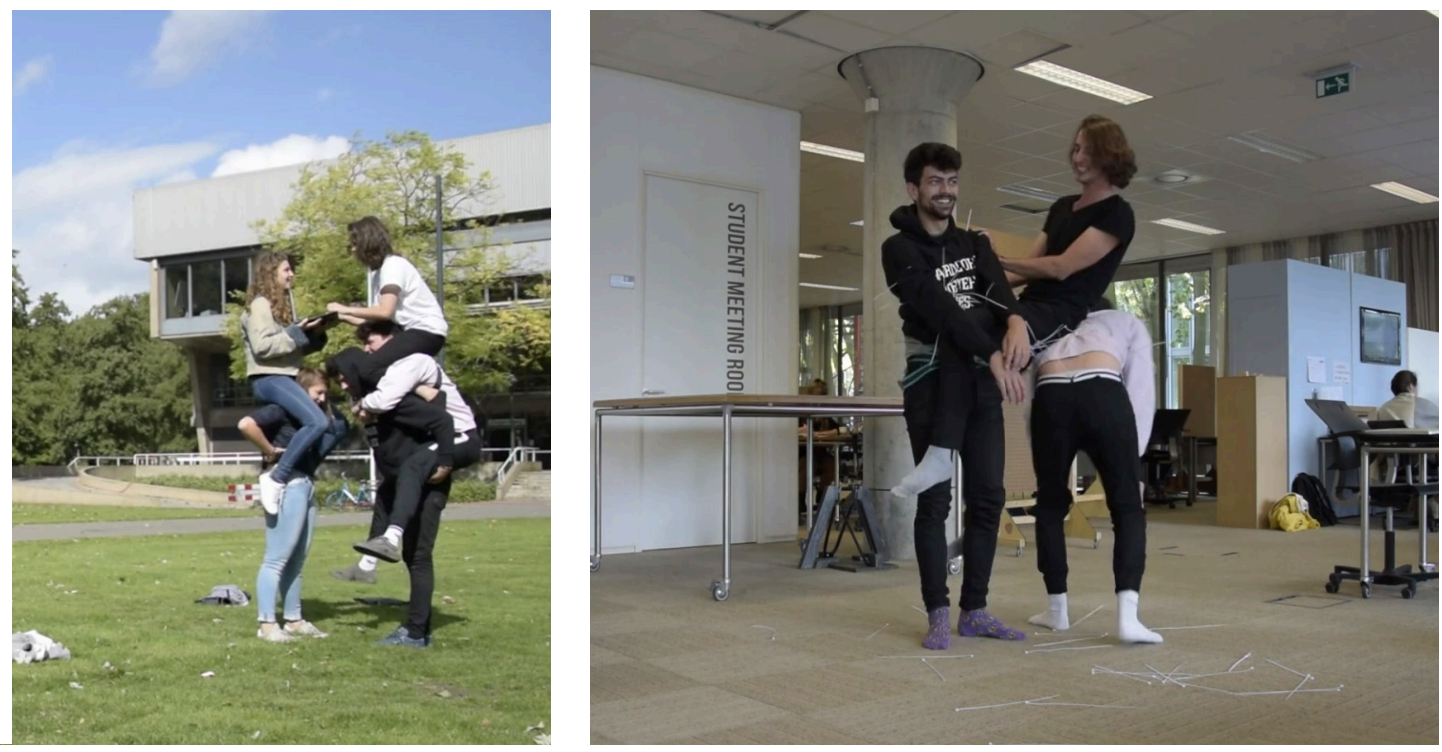

Exploration 3: Humanized work units 


\section{Exploration 4: The Underwater Office}

The underwater office was a key experience in our speculative design process. In the underwater office, one of the authors explored different work behaviors under water. Could working under water improve our physical health and well-being in the office? It is a weird thought perhaps yet not completely unreasonable. There are two important health benefits which made it worthwhile to consider during our explorations: (1) being under water your body is almost floating, meaning there is no uneven stress on your body, which you normally do have when sitting in a chair, (2) moving under water requires more effort due to the increased resistance of water instead of air on the upright human body. In a first session, the author watched a documentary, projected on the pool floor, while fully submerged. This required a lot of physical efforts and constant movement to stay close to the projection. The second session included an adapted, self-made water-proof keyboard for the underwater office. The underwater office exploration allowed to think beyond conventional ways of ordering space and ways of relating to it. Because water disarms the pull of gravity it can relieve physical stress that can build-up after sitting for too long. Although this is beneficial, it can also stimulate natural laziness by just floating around. Our explorations represented several perspectives on rethinking ways of working. We evolved from simplistic explorations of different sitting postures in a traditional workspace, to interrogations about mobility and constraints linked to computerized work. We eventually reached a more fundamental focus on organic bodily experiences, shared or individual. This became the cornerstone of the next iteration, which embodies the notion of 'wildness' in working practices.

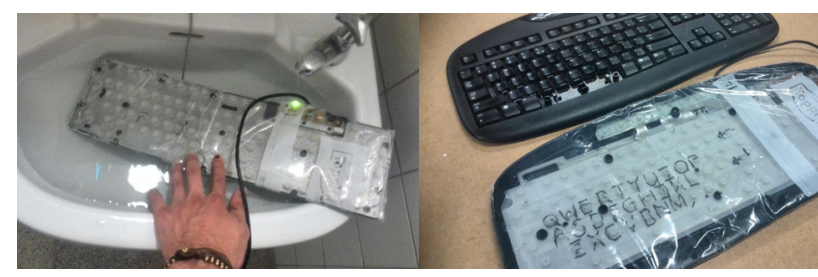

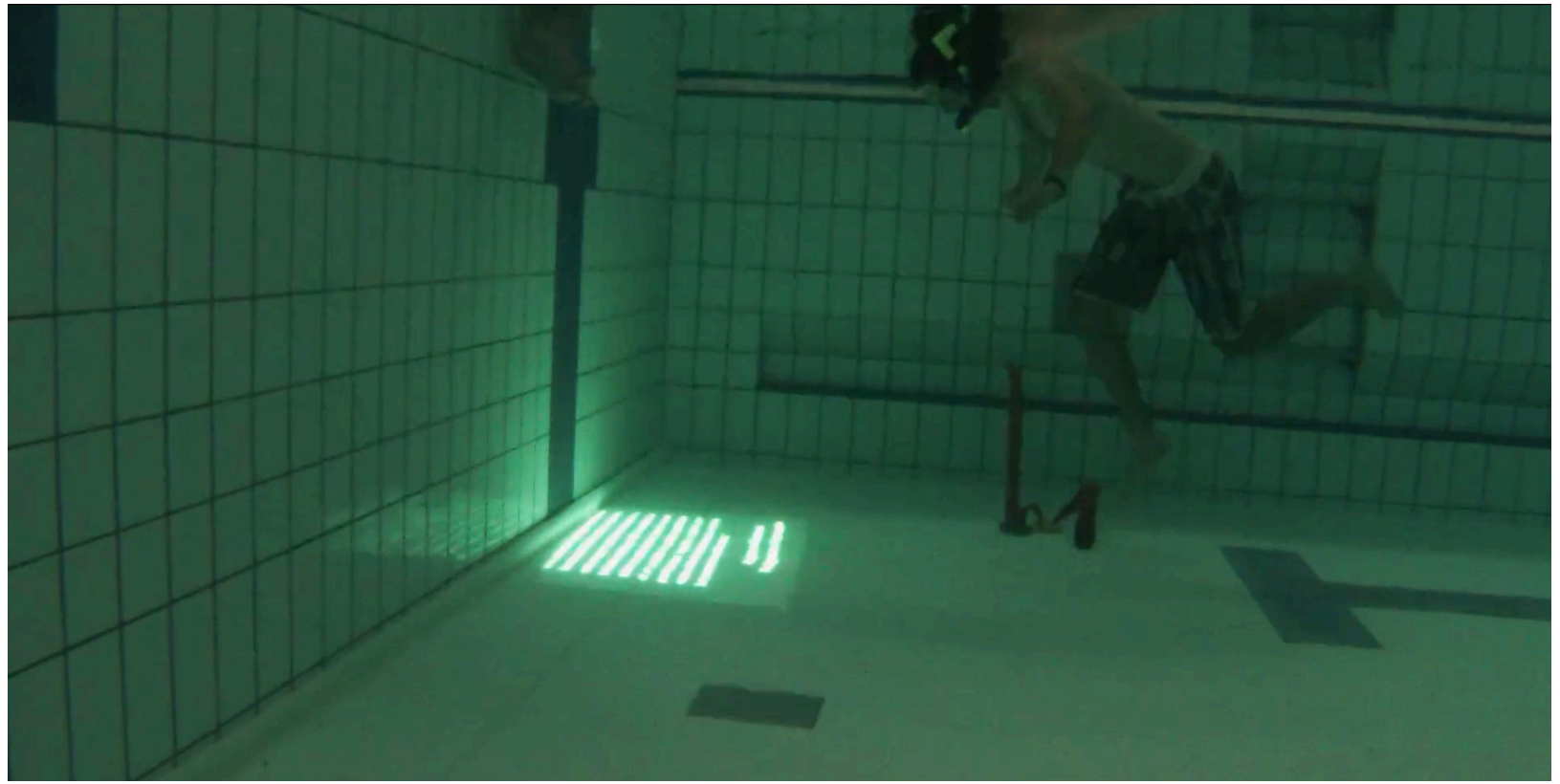

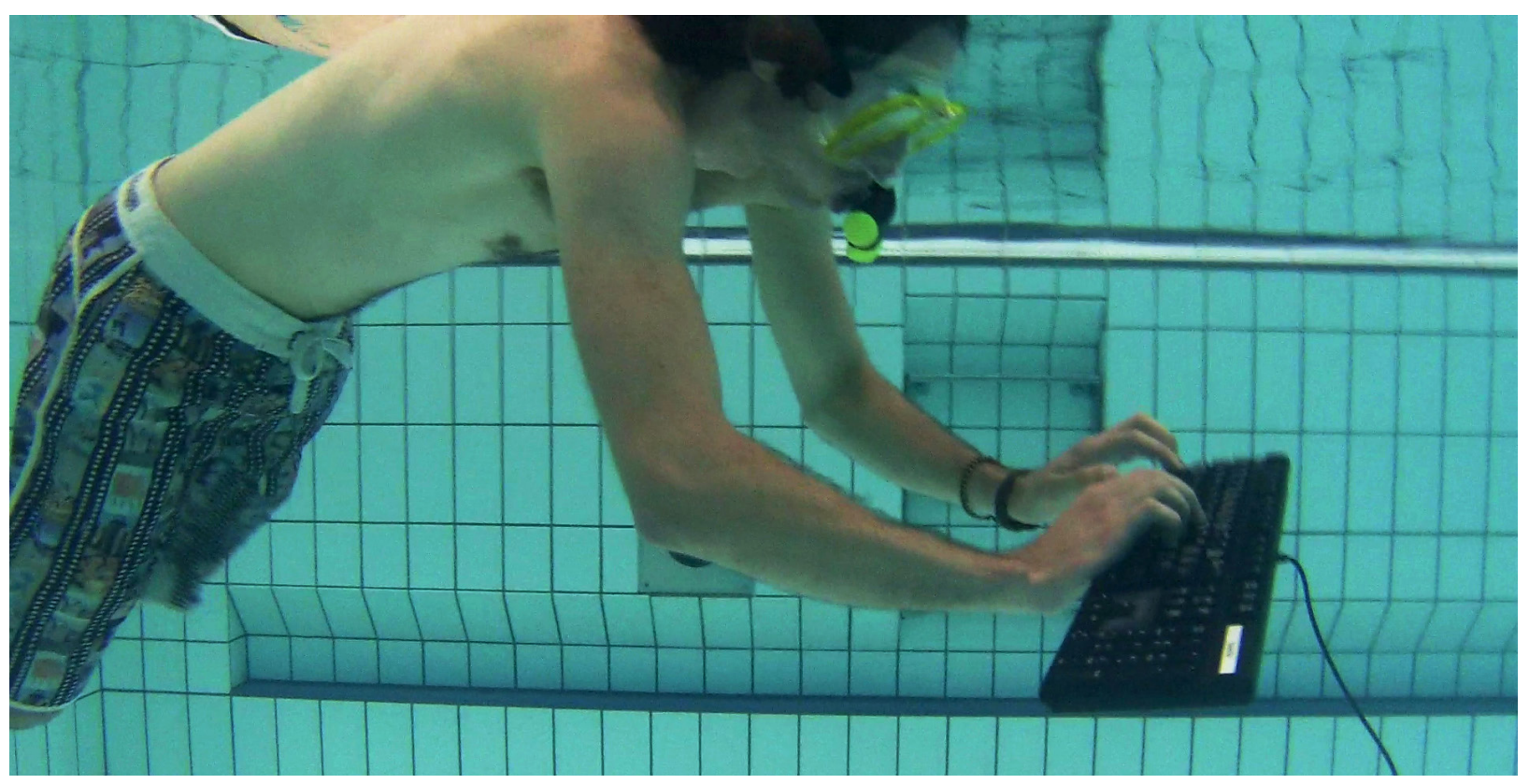

Exploration 4: The underwater office 


\section{THE OFFICE JUNGLE}

\section{Material and Shape Exploration}

Based on the insights gathered in our explorations, we carried out several material and shape explorations. These explorations led to a first iteration of "The Office Jungle". The Office Jungle is a proposition for a new 'wild' office environment. Instead of fixed static floors, walls and ceilings, we propose a new dynamic setting that encourages office workers to change the way they move and move around in an office space.

The first Office Jungle model started as a rhombicosidodecahedron made from PVC conduit cut in $300 \mathrm{~mm}$ pieces and cheap $340 \mathrm{~mm}$ long tie-wraps. A consecutive iteration was a truncated icosahedron made from PVC conduit cut in two lengths, $300 \mathrm{~mm}$ and $330 \mathrm{~mm}$, and extra-strong $370 \mathrm{~mm}$ long tie-wraps. In its current form, The Office Jungle is shaped as a suspended geodesic structure made of 270 wooden rods and shock cord.

\section{First Technology Implementation}

The Office Jungle demonstrator is a stand-alone piece of furniture to evoke the wildness in the office. The vision would however involve an entire space. As people during the design process kept misunderstanding the concept as a piece of furniture, we designed an interactive scale-model $(1: 10)$ allowing to showcase the technical aspects.

An Arduino Uno was used with a motor shield to control the DC motors, which moved the Office Jungle in the scale-model. For the input, a temperature/ humidity sensor (DHT11) and light sensor (LDR) were implemented. The idea was that Office Jungle would respond to the atmospheric factors of the environment and 'move' with the weather (not on a linear basis though, as some unpredictability would benefit the vision) rather than being based on direct user input.
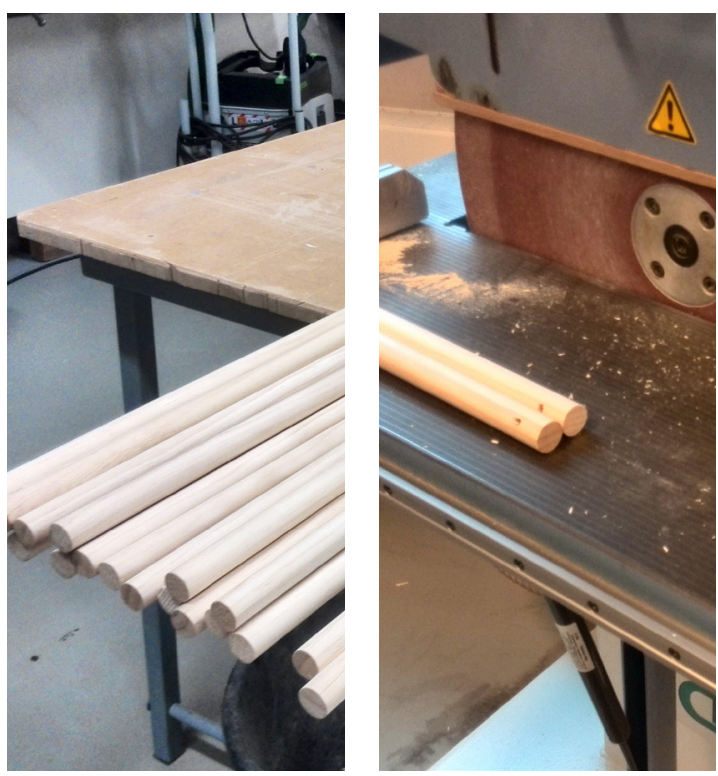

Design Office Jungle

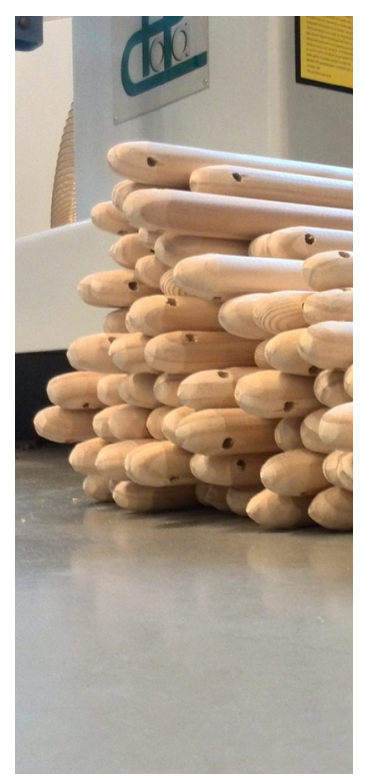

$\longrightarrow$
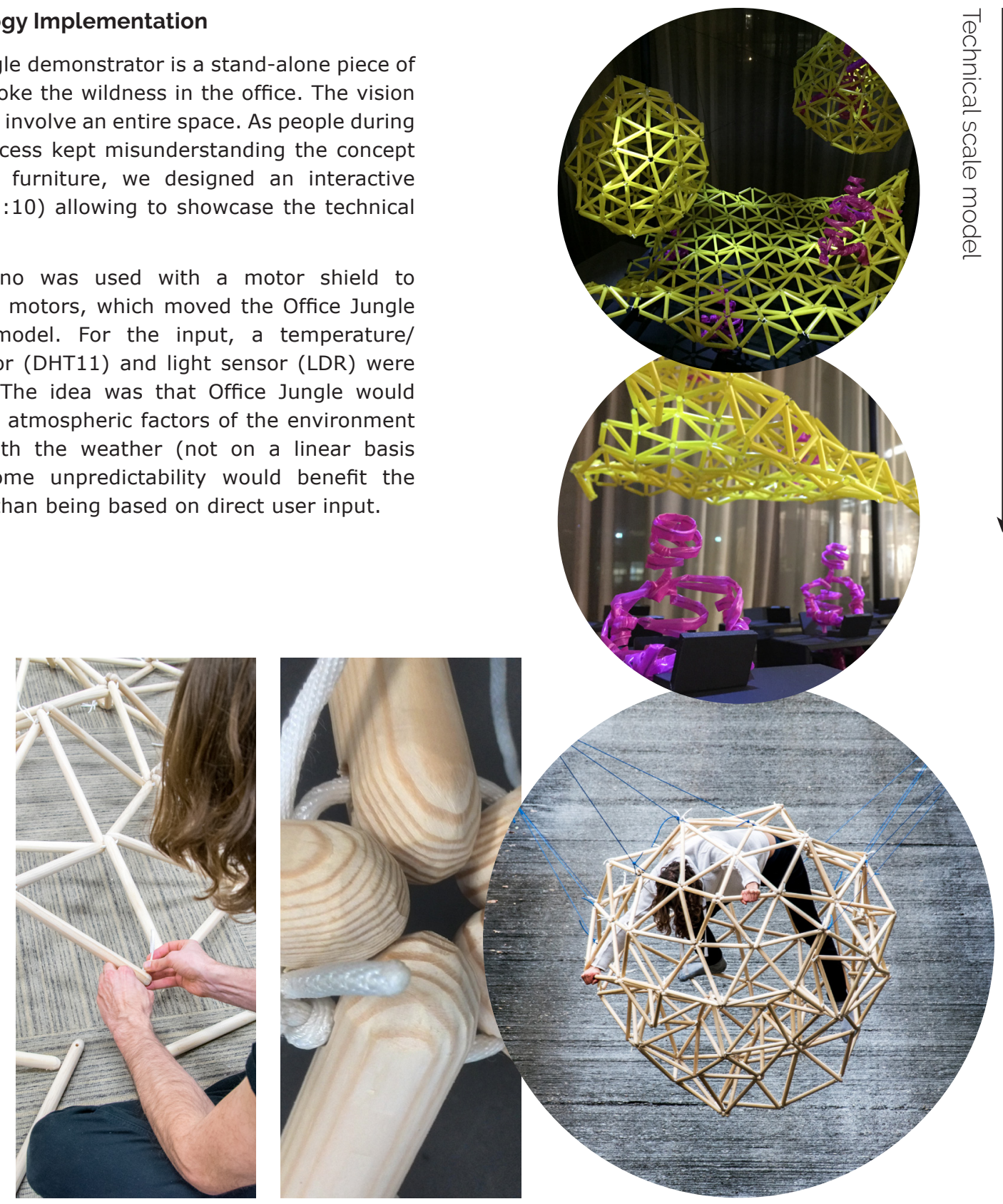


\section{The Office Jungle as a Design Exemplar}

The Office Jungle functions as a design exemplar of a 'wild' office place, made to experience the interaction between a 'wild' environment and our work behaviour. The Office Jungle can take many shapes and forms. A wild office environment rests upon three underlying values. It should:

1) be a dynamic and changing environment that requires more cognitive effort compared to a regular office space.

2) be an environment that invites physical activity and reacts to movement preferably in a non-deterministic fashion.

3) focus on consistency and adaptation and allow for self-organization as an inherent part of wildness.

Wildness is defined as "a quality of interactive processing between an organism and its surroundings in which the realities of base natures are met, allowing the construction of durable systems" [3]. Wildness in the office could thus create a more durable environment as compared to our current practice. Wildness can be used in opposition to artificial [3]. In the office context, more wildness is needed to counterbalance our "cultivated" and sedentary work practices. Wildness produces a basis for consistency and adaptation, resulting in a stable basis for interaction [3]. This being in contrasts to artificial systems that reject wildness and stimulate rapid change [3]. By adopting wildness, the office environment may find a new healthy equilibrium.

The design is adaptable enough to support various body types and has been pilot tested with people from different age, body shapes and fitness level. Weight and body inclusivity are important factors to consider to foster the adoption of wildness.
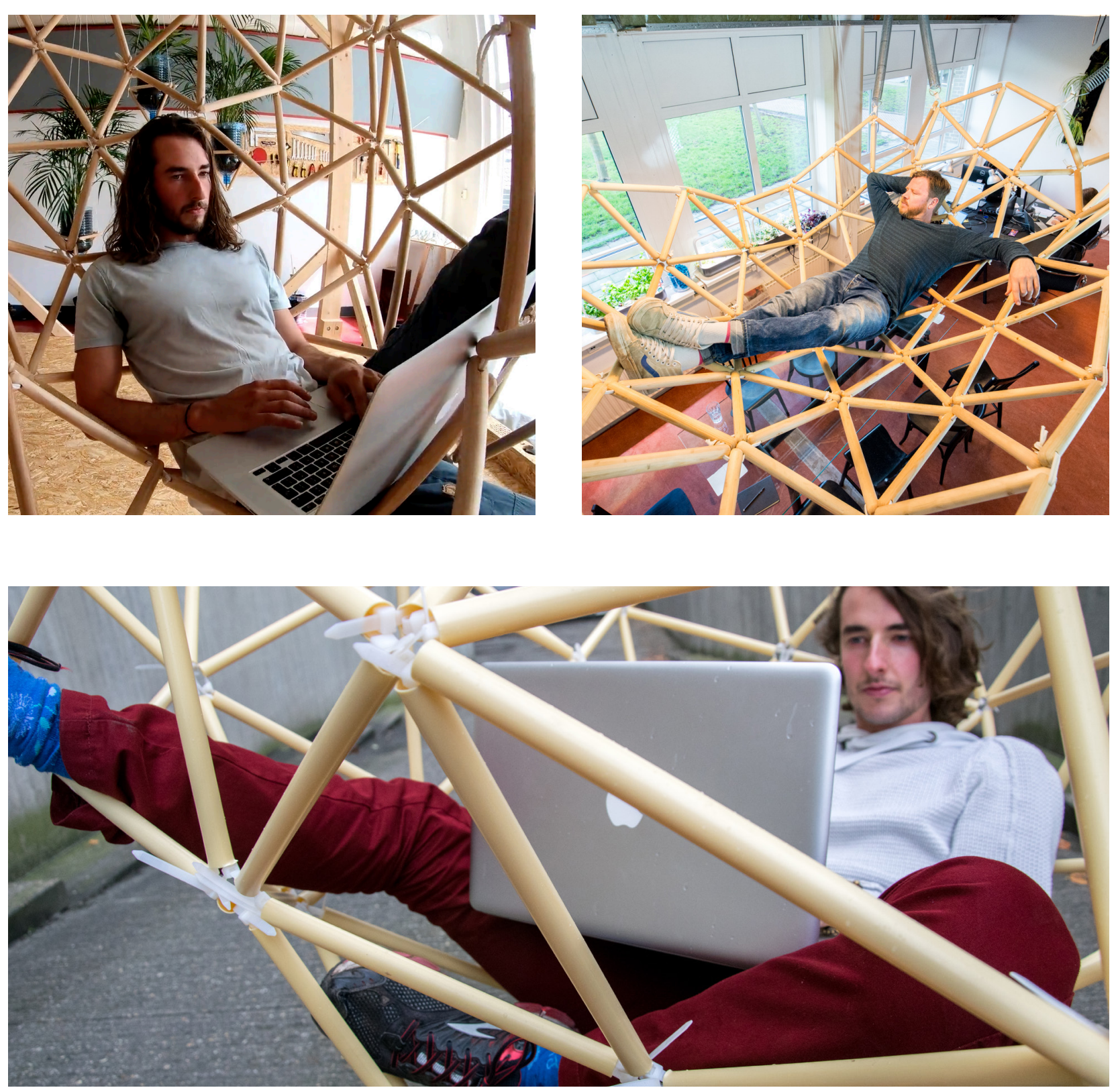


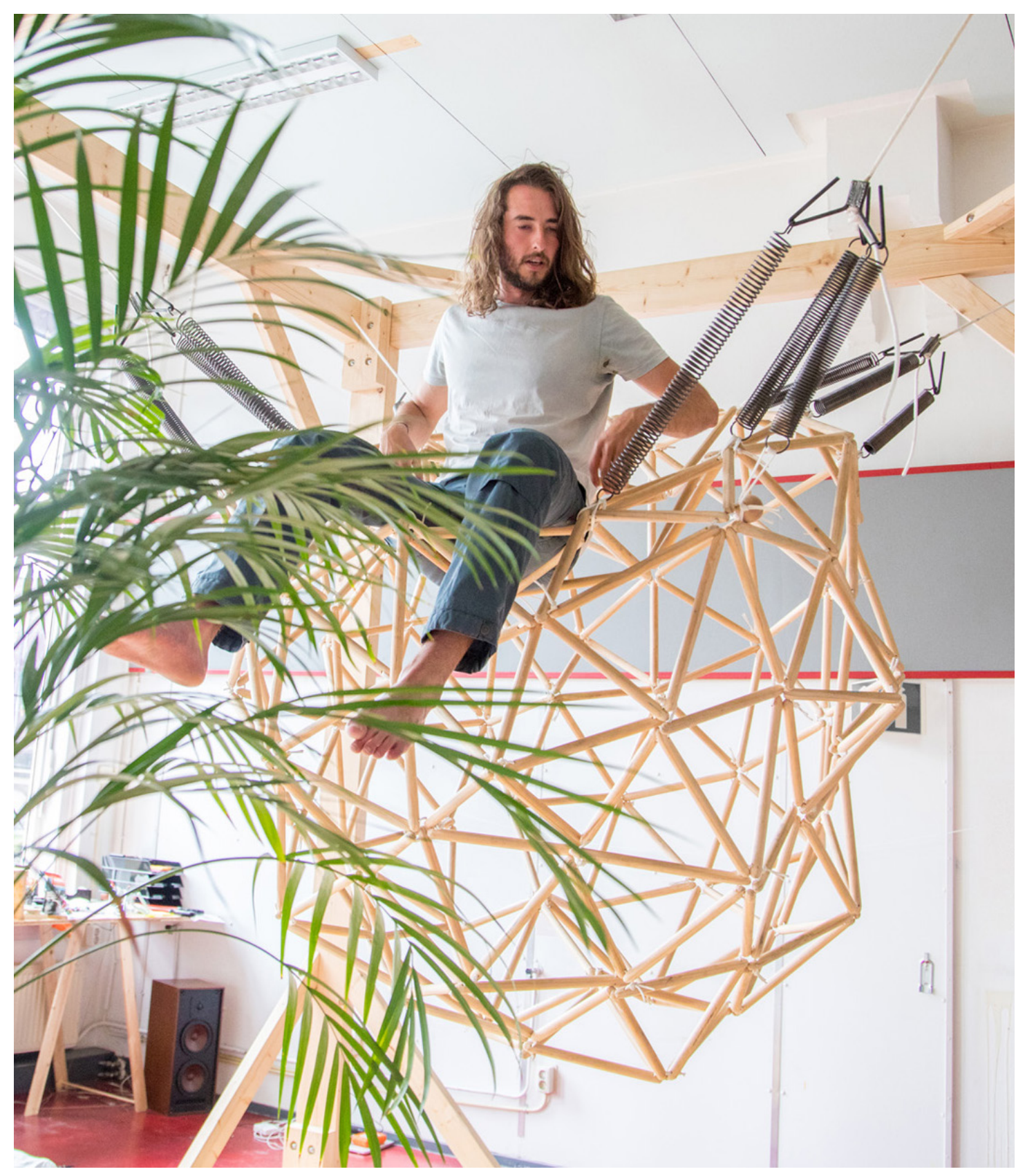

\section{DISCUSSION}

\section{Technology in the Workplace}

Based on observations of users, and a first-person experience of living with the Office Jungle for three years, we can reflect on the way this installation shapes the use of technology. It is possible to use a laptop in the Jungle, yet it is not optimal and implies a more static position that would restrict movement. The mobility of the structure might naturally discourage sedentary behaviors. Phones and tablets work better but do nevertheless limit the availability of users' hands, essential to move within the structure. The suitability of current technologies overall depends on the use situations: some working tasks can already be achieved (e.g. attending a conference, audio call, dictating text to a voice assistant). Still, The Office Jungle might call for adapted technologies, which do not constraint mobility as much as current computer mediated work. In this sense, The Office Jungle provides a new landscape to think about novel ways of involving interactive systems in the working environment, such as speechrecognition, wearable technology or even Brain-Computer Interfaces.

\section{Challenging the Status Quo}

The Office Jungle suggests a new approach toward office work and office design, calling for more wildness in the office environment to counterbalance our increasingly sedentary office workstyle. As a critical design, The Office Jungle questions our increasing sedentary lives by questioning and raising awareness of current work practices. The project is intended to spark a conversation rather than a solution per se. As argued by Dunne and Raby [8], critical design can provide 'speculative design proposals' that 'challenge narrow assumptions, preconceptions and givens about the role products play in everyday life'. Critical designs are therefore often not intended for implementation at a large scale and do not prioritize feasibility and commercial purposes.

The Office Jungle has been exhibited at several venues, and the public invited to interact with it. Dozens of people from all backgrounds tried it out and commented on it. Some people were primarily curious about the level of comfort and the different (working) postures the Office Jungle would support. Many children adopted a playful attitude seeing it as a playground object. Finally, some visitors attempted to challenge their own fitness as well as the robustness of the prototype by pushing the boundaries of bouncing, jumping, and climbing. 


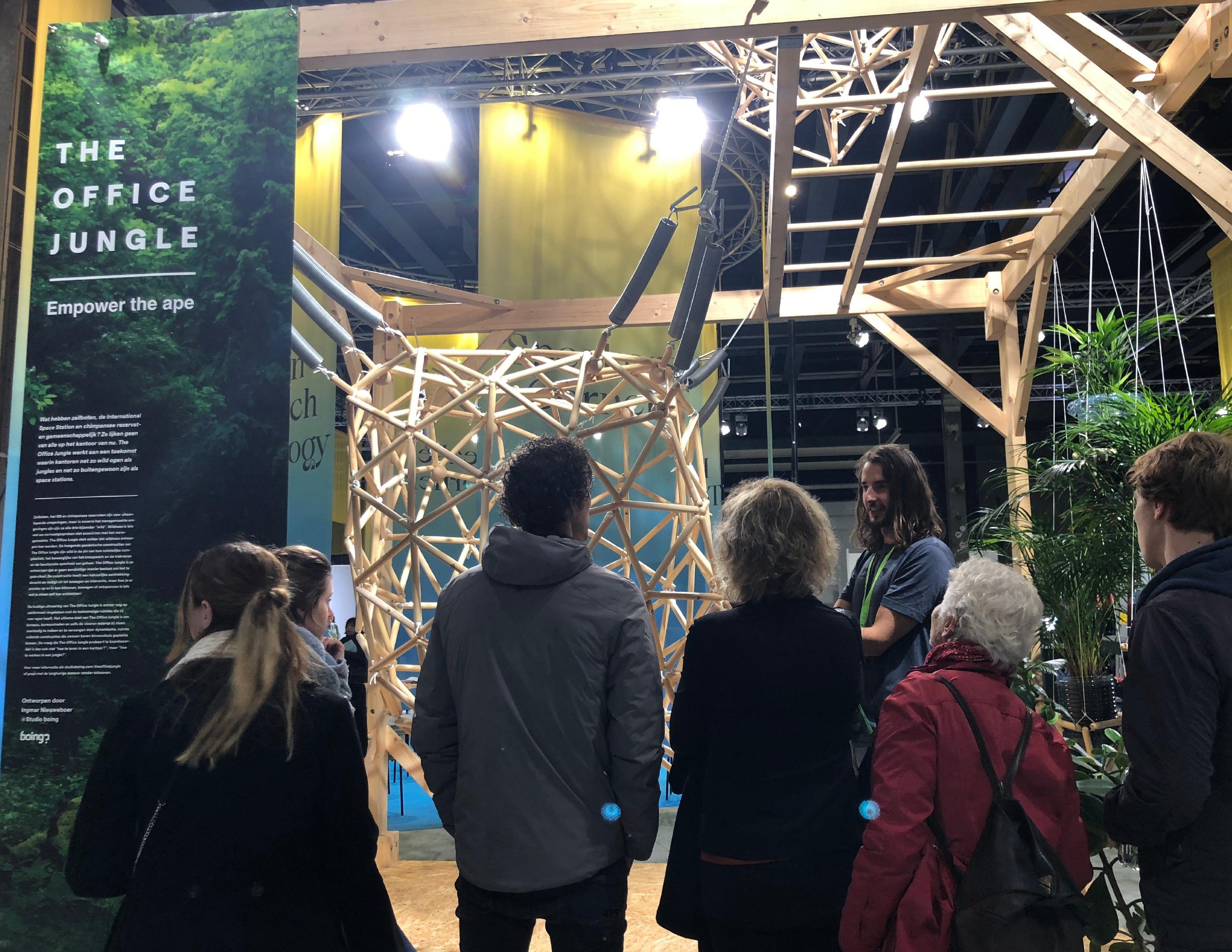




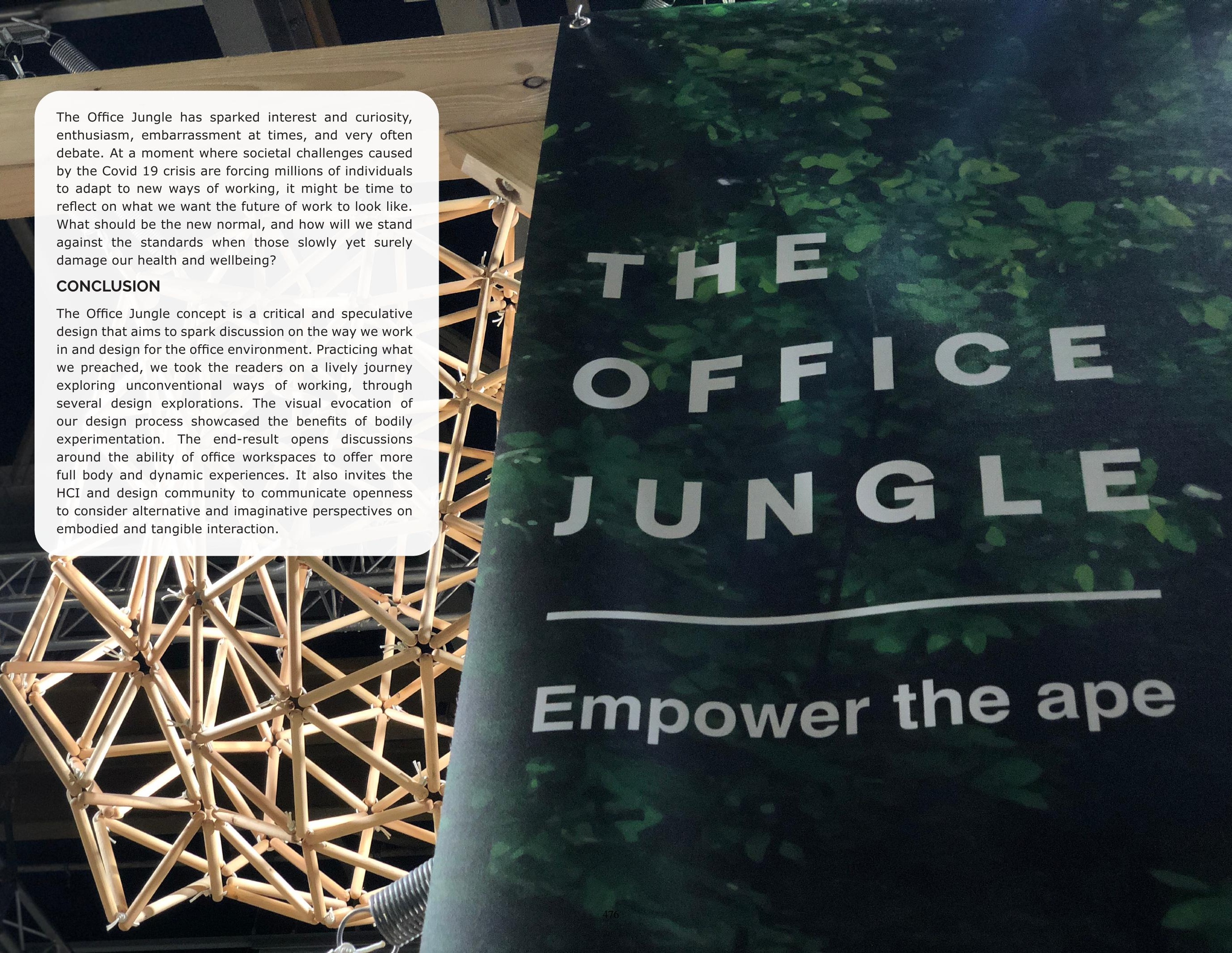




\section{REFERENCES}

[1] James Auger. 2013. Speculative design: Crafting the speculation. Digital Creativity 24, 1: 11-35.

[2] Simone Caljouw, Eise De Haan, N. Mollee, and Rob Withagen. 2019. The End of Sitting: How middle-aged employees use and experience a new activity-inducing office over time. Journal of Environmental Psychology 61: 138-141. https:// doi.org/10.1016/j.jenvp.2019.01.001

[3] Lawrence J. Cookson. 2011. A definition for wildness. Ecopsychology 3, 3: 187-193.

[4] Ida Damen, Hans Brombacher, Carine Lallemand, Rens Brankaert, Aarnout Brombacher, Pieter van Wesemael, and Steven Vos. 2020. A Scoping Review of Digital Tools to Reduce Sedentary Behavior or Increase Physical Activity in Knowledge Workers. International Journal of Environmental Research and Public Health 17, 2: 499. https:// doi.org/10.3390/ijerph17020499

[5] Ida Damen, Lidewij Heerkens, Annabel van den Broek, Kimberly Drabbels, Olga Cherepennikova, Hans Brombacher, and Carine Lalle-mand. 2020. PositionPeak: Stimulating Position Changes During Meetings. In Extended Ab-stracts of the 2020 CHI Conference on Human Factors in Computing Systems. https://doi. org/10.1145/3334480.3383054
[6] Ida Damen, Daphne Menheere, Carine Lallemand, and Steven Vos. 2020. Ivy: Reading a Critical Design for Sedentary Behavior in the Office Context. Proceedings of the 2020 ACM Designing Interactive Systems Conference. https://doi. org/10.1145/3393914.3395893

[7] Jelle van Dijk, Camille Moussette, Stoffel Kuenen, and Caroline Hummels. 2013. Radical clashes. In Proceedings of the 7th Interna-tional Conference on Tangible, Embedded and Embodied Interaction - TEI '13. https://doi. org/10.1145/2460625.2460680

[8] Anthony Dunne and Fiona Raby. Critical Design FAQ. Retrieved October 12, 2019 from http:// dunneandraby.co.uk/content/bydandr/13/0.

[9] Fabian Hemmert, Piet Becker, Alexander Görts, David Hrlic, David Von Netzer, and Christopher J. Weld. 2019. Aicracy: Everyday objects from a future society governed by an artifical intelligence. ACM International Conference Proceeding Series: 451-456.

[10] Yitong Huang, Steve Benford, and Holly Blake. 2019. Digital Interventions to Reduce Sedentary Behaviors of Office Workers: Scoping Review. Journal of Medical Internet Research 21, 2: e11079. https://doi.org/10.2196/11079
[11] Scott R. Klemmer, Björn Hartmann, and Leila Takayama. 2006. How bodies matter. In Proceedings of the 6th ACM conference on Designing Interactive systems - DIS '06. https://doi. org/10.1145/1142405.1142429

[12] James A. Levine. 2015. Sick of sitting. Diabetologia 58, 8: $1751-1758$

[13] Matt Malpass. 2016. Critical Design Practice: Theoretical Perspectives and Methods of Engagement. The Design Journal 19, 3: 473-489.

[14] Kathrin Probst, Florian Perteneder, Jakob Leitner, Michael Haller, Andreas Schrempf, and Josef Glöckl. 2012. Active office. In Proceedings of the 2012 ACM annual conference extended abstracts on Human Factors in Computing Systems Extended Abstracts - CHI EA '12. https://doi. org/10.1145/2212776.2223770

[15] Helena Tobiasson, Anders Hedman and Yngve Sundblad. 2014. Still at the office: designing for physical movement-inclusion during office work. IHC. 